Article

Subscriber access provided by King Abdullah University of Science and Technology Library

\title{
Temperature dependence of electrocatalytic and photocatalytic oxygen evolution reaction rates using NiFe oxide
}

Ela Nurlaela, Tatsuya Shinagawa, Muhammad Qureshi, Dattatray Sadashiv Dhawale, and Kazuhiro Takanabe ACS Catal., Just Accepted Manuscript • DOI: 10.1021/acscatal.5b02804 • Publication Date (Web): 25 Jan 2016

Downloaded from http://pubs.acs.org on February 1, 2016

\section{Just Accepted}

"Just Accepted" manuscripts have been peer-reviewed and accepted for publication. They are posted online prior to technical editing, formatting for publication and author proofing. The American Chemical Society provides "Just Accepted" as a free service to the research community to expedite the dissemination of scientific material as soon as possible after acceptance. "Just Accepted" manuscripts appear in full in PDF format accompanied by an HTML abstract. "Just Accepted" manuscripts have been fully peer reviewed, but should not be considered the official version of record. They are accessible to all readers and citable by the Digital Object Identifier (DOI®). "Just Accepted" is an optional service offered to authors. Therefore, the "Just Accepted" Web site may not include all articles that will be published in the journal. After a manuscript is technically edited and formatted, it will be removed from the "Just Accepted" Web site and published as an ASAP article. Note that technical editing may introduce minor changes to the manuscript text and/or graphics which could affect content, and all legal disclaimers and ethical guidelines that apply to the journal pertain. ACS cannot be held responsible for errors or consequences arising from the use of information contained in these "Just Accepted" manuscripts. 


\title{
Temperature dependence of electrocatalytic and
}

\section{photocatalytic oxygen evolution reaction rates using}

\section{NiFe oxide}

\author{
Ela Nurlaela, ${ }^{\dagger}$ Tatsuya Shinagawa, ${ }^{\dagger}$ Muhammad Qureshi, Dattatray S. Dhawale, Kazuhiro \\ Takanabe*
}

King Abdullah University of Science and Technology (KAUST), KAUST Catalysis Center (KCC), Physical Sciences and Engineering Division (PSE), 4700 KAUST, Thuwal, 23955-6900, Saudi Arabia.

$[\dagger]$ These authors contributed equally to this work

\begin{abstract}
The present work compares oxygen evolution reaction (OER) in electrocatalysis and photocatalysis in aqueous solutions using nanostructured $\mathrm{NiFeO}_{\mathrm{x}}$ as catalysts. The impacts of $\mathrm{pH}$ and reaction temperature on the electrocatalytic and photocatalytic OER kinetics were investigated. For electrocatalysis, a $\mathrm{NiFeO}_{\mathrm{x}}$ catalyst was hydrothermally decorated on $\mathrm{Ni}$ foam. In $1 \mathrm{M} \mathrm{KOH}$ solution, the $\mathrm{NiFeO}_{\mathrm{x}}$ electrocatalyst achieved $10 \mathrm{~mA} \mathrm{~cm}$ at an overpotential of
\end{abstract}


$260 \mathrm{mV}$. The same catalyst was decorated on the surface of $\mathrm{Ta}_{3} \mathrm{~N}_{5}$ photocatalyst powder. The reaction was conducted in the presence of $0.1 \mathrm{M} \mathrm{Na}_{2} \mathrm{~S}_{2} \mathrm{O}_{8}$ as a strong electron scavenger, thus likely leading to the OER being kinetically relevant. When compared with the bare $\mathrm{Ta}_{3} \mathrm{~N}_{5}$, $\mathrm{NiFeO} / \mathrm{Ta}_{3} \mathrm{~N}_{5}$ demonstrated a 5-fold improvement in photocatalytic activity in the OER under visible light irradiation, achieving a quantum efficiency of $24 \%$ at $480 \mathrm{~nm}$. Under the conditions investigated, a strong correlation between the electrocatalytic and photocatalytic performances was identified: an improvement in electrocatalysis corresponded with an improvement in photocatalysis without altering the identity of the materials. The rate change at different $\mathrm{pH}$ was likely associated with electrocatalytic kinetics that accordingly influenced the photocatalytic rates. The sensitivity of the reaction rates with respective to the reaction temperature resulted in an apparent activation energy of $25 \mathrm{~kJ} \mathrm{~mol}^{-1}$ in electrocatalysis, whereas that in photocatalysis was $16 \mathrm{~kJ} \mathrm{~mol}^{-1}$. The origin of the difference in these activation energy values is likely attributed to the possible effects of temperature on the individual thermodynamic and kinetic parameters of the reaction process. The work described herein demonstrates a method of "transferring the knowledge of electrocatalysis to photocatalysis" as a strong tool to rationally and quantitatively understand the complex reaction schemes involved in photocatalytic reactions.

\section{KEYWORDS}

Photocatalysis, electrocatalysis, oxygen evolution reaction, nickel-iron oxide, kinetics

\section{INTRODUCTION}


The conversion of solar energy using semiconductor powder suspension systems has attracted significant attention due to its potential for an economic and scalable production of clean energy. $^{1-6}$ The classical photocatalyst powder mainly consists of two components: a semiconductor powder as a photon absorber and electrocatalyst particles (often called cocatalyst) on the semiconductor surface. The added cocatalyst is considered to have dual functions: improving charge separation and electrocatalysis. However, few studies have quantitatively investigated the relationship between electrocatalytic and photocatalytic performances. On the one hand, electrocatalytic rates are separately measurable by electrochemical means by precisely controlling the applied potential. On the other hand, photocatalytic rates are measurable only by quantifying evolved gases and thus lack information on the potentials of materials under working conditions. Catalyst potentials on semiconductors have only been captured with probe molecules utilizing spectroscopic techniques. ${ }^{7-8}$

Our ongoing efforts include improving photocatalytic efficiencies by using tantalum nitride $\left(\mathrm{Ta}_{3} \mathrm{~N}_{5}\right)$ as a photon absorber. The $\mathrm{Ta}_{3} \mathrm{~N}_{5}$ photocatalyst exhibits an n-type character with relative stability during photocatalytic oxygen evolution reaction (OER), ${ }^{9-13}$ possessing a bandgap of approximately $2.1 \mathrm{eV}$, which corresponds to a theoretical solar-to-hydrogen conversion efficiency of $15.9 \%{ }^{14}$ Importantly, our previous work on $\mathrm{Ta}_{3} \mathrm{~N}_{5}$ thin films for the photoelectrochemical OERs noted the necessity of surface decorations for successful photocatalytic OER. $\mathrm{Ta}_{3} \mathrm{~N}_{5}$ suffers from very low carrier transport properties and fast carrier recombination $(<10 \mathrm{ps})$ in the absence of surface modification despite its suitable absorption in the visible-light range. ${ }^{15}$ Several studies have focused on modifying $\mathrm{Ta}_{3} \mathrm{~N}_{5}$ photocatalyst surfaces with cocatalysts, ${ }^{15-19}$ e.g., cobalt oxide. ${ }^{19}$ A highly active OER electrocatalyst is desirable as a catalyst for a successful photocatalytic water splitting reaction. Recently, literature has re- 
discovered that the edge-sharing octahedral $\mathrm{NiFeO}_{\mathrm{x}}$ catalyst exhibits one of the highest OER activities in alkaline solution. ${ }^{20-23}$ Specifically, a study disclosed that $\mathrm{NiFeO}_{\mathrm{x}}$ synthesized by pulsed-laser ablation required a mere $260 \mathrm{mV}$ overpotential at $10 \mathrm{~mA} \mathrm{~cm}^{-2}{ }^{23}$ Another report demonstrated a stable $\mathrm{NiFeO}_{\mathrm{x}}$ performance at an onset potential below $1.5 \mathrm{~V}$ on the reversible hydrogen electrode (RHE) scale. ${ }^{22,24}$

The present study investigated an efficient photocatalytic OER using a $\mathrm{Ta}_{3} \mathrm{~N}_{5}$ photocatalyst decorated with a $\mathrm{NiFeO}_{\mathrm{x}}$ catalyst. The study attempted to transfer the knowledge obtained in electrocatalysis into photocatalysis. Such an effort is effective because the electrocatalytic can quantitatively determine a potential-activity correlation, which would be difficult in a photocatalytic suspension system. The photocatalytic reaction was conducted in the presence of 0.1 $\mathrm{M} \mathrm{Na}_{2} \mathrm{~S}_{2} \mathrm{O}_{8}$ as a strong electron scavenger, thus likely leading to the OER being a kinetic bottle-neck. We focused on the sensitivity of electrocatalytic and photocatalytic rates on solute concentration and temperature. Our comprehensive discussion also addressed the temperature dependency of associated parameters, such as photophysical processes in the semiconductor and ion migration in solution (e.g., solution resistance). We claim that correlating electrochemical measurement with photocatalysis is a strong tool to understanding the photocatalytic process.

\section{EXPERIMENTAL SECTION}

$\mathrm{NiFeO}_{\mathbf{x}}$ synthesis: Nanostructured porous $\mathrm{NiFeO}_{\mathrm{x}}$ on $\mathrm{Ni}$ foam $(\mathrm{NF}, 1.6 \mathrm{~mm}$ thick, pore size $0.5 \mathrm{~mm}, 48-52$ cells/inch, $7500 \mathrm{~m}^{2} / \mathrm{m}^{3}$, Nilaco) was synthesized by a simple and scalable hydrothermal approach as described in the literature. ${ }^{25}$ In a typical synthesis procedure, 1.03 mmol of $\mathrm{Ni}\left(\mathrm{NO}_{3}\right)_{2} \cdot 6 \mathrm{H}_{2} \mathrm{O}(99.999 \%$, Sigma-Aldrich $), 0.990 \mathrm{mmol}$ of $\mathrm{Fe}\left(\mathrm{NO}_{3}\right)_{2} \cdot 9 \mathrm{H}_{2} \mathrm{O}(99.99 \%$, Sigma-Aldrich) and $5.00 \mathrm{mmol}$ of $\mathrm{CO}\left(\mathrm{NH}_{2}\right)_{2}(>99.5 \%$, Sigma-Aldrich) were first mixed in 80 
$\mathrm{mL}$ of an aqueous solution under vigorous stirring at room temperature for $10 \mathrm{~min}$. The solution was transferred into a 50-mL Teflon-lined stainless-steel autoclave. The NF substrate was placed in the solution after cleaning with $0.1 \mathrm{M} \mathrm{HCl}$ in an ultrasound bath for $5 \mathrm{~min}$ to remove the native surface oxide layer. Further washing was conducted with Milli-Q water $(18.2 \mathrm{k} \Omega)$ and ethanol in the ultrasound bath for $5 \mathrm{~min}$. The sealed autoclave was transferred to an oven to carry out a heat treatment out at $393 \mathrm{~K}$ for $12 \mathrm{~h}$. Notably, the precipitation of $\mathrm{Ni}$ and Fe nitrides was induced by the decomposition of urea at the elevated temperature (which releases a mixture of ammonium and carbonate ions). ${ }^{25-27}$ For the control experiment, monometallic Ni or Fe on the NF was prepared in the same manner.

Ta ${ }_{3} \mathrm{~N}_{5}$ synthesis: $\mathrm{Ta}_{3} \mathrm{~N}_{5}$ semiconductor photocatalyst was prepared from as-purchased crystalline $\mathrm{Ta}_{2} \mathrm{O}_{5}\left(\geq 99.99 \%\right.$ metal basis, $<5 \mu \mathrm{m}$, Sigma-Aldrich) by applying direct $\mathrm{NH}_{3}$ nitridation at a high temperature. ${ }^{16,28}$ A total amount of $0.5 \mathrm{~g} \mathrm{Ta}_{2} \mathrm{O}_{5}$ was wrapped in quartz wool and placed in a tube furnace (inner diameter: $26 \mathrm{~mm}$ ) to provide a homogeneous nitrided product. The tube furnace was initially purged with $\mathrm{N}_{2}$ before the introduction of $\mathrm{NH}_{3}$ flow at room temperature. The furnace temperature was raised to $1173 \mathrm{~K}$ at a heating rate of $5 \mathrm{~K} \mathrm{~min}^{-1}$. Nitridation was conducted at the temperature for $15 \mathrm{~h}$ under an $\mathrm{NH}_{3}$ flow of $200 \mathrm{~mL} \mathrm{~min}{ }^{-1}$. The sample was allowed to cool to room temperature inside the tube furnace under $\mathrm{NH}_{3}$ flow.

Decoration of $\mathrm{Ta}_{3} \mathrm{~N}_{\mathbf{5}}$ with $\mathrm{NiFeO}_{\mathbf{x}}$ : A total amount of $1 \mathrm{~g}$ of $\mathrm{Ta}_{3} \mathrm{~N}_{5}$ was added into $30 \mathrm{~mL}$ aqueous solution that contained between 4.21 to $25.3 \mathrm{mM}$ of both of $\mathrm{Ni}\left(\mathrm{NO}_{3}\right)_{2} \cdot 6 \mathrm{H}_{2} \mathrm{O}$ and $\mathrm{Fe}\left(\mathrm{NO}_{3}\right)_{2} \cdot 9 \mathrm{H}_{2} \mathrm{O}$. The mixture was stirred for $4 \mathrm{~h}$ and then transferred into a $50-\mathrm{mL}$ Teflon-lined stainless-steel autoclave. A heat treatment was carried out at $393 \mathrm{~K}$ for $12 \mathrm{~h}$, and the solution was allowed to cool to room temperature. The resultant suspension was repeatedly centrifuged. The 
obtained powder after filtration in Milli-Q water was dried in an oven at $353 \mathrm{~K}$ for $12 \mathrm{~h}$. Also, the $\mathrm{Ta}_{3} \mathrm{~N}_{5}$ semiconductor was decorated with $\mathrm{NiO}_{\mathrm{x}}$ in the same manner.

Characterizations: The crystal structure was analyzed by X-ray diffraction (XRD) with a Bruker D8 Advanced A25 diffractometer in the Bragg-Brentano geometry (with Cu- $\mathrm{K}_{\alpha}$, at $40 \mathrm{kV}$ and $40 \mathrm{~mA}$ ) using a linear position sensitive detector (opening $2.9^{\circ}$ ). The diffractometer was configured with a $0.44^{\circ}$ diverging slit, a $2.9^{\circ}$ antiscattering slit, $2.5^{\circ}$ Soller slits, and a nickel filter to attenuate the contributions from $\mathrm{Cu}-\mathrm{K}_{\beta}$ fluorescence. Data sets were acquired in continuous scanning mode over a $2 \theta$ range of $10-80^{\circ}$. X-ray photoelectron spectroscopy (XPS) spectra were obtained with an AMICUS KRATOS using Mg/Al anodes at $12 \mathrm{kV}$ and $10 \mathrm{~mA}$. A peak maximum of $\mathrm{C} 1 \mathrm{~s}$ at $284.6 \mathrm{eV}$ was used as an internal standard to correct the binding energies. Induced coupled plasma (ICP) measurements were performed using an ICP-OES Varian 72 ES, and the loaded amounts of catalysts are reported using the measured values. Scanning electron microscopy (SEM) images were collected on a Nova Nano 630 scanning electron microscope from FEI Company. Transmission electron microcopy (TEM) images of the samples were captured at $300 \mathrm{kV}$ with a Titan G2 80-300 CT microscope (FEI Company, Hillsboro, OR), which was equipped with an EDS detector, a post-column energy filer, and a charged-coupled device (CCD) camera. TEM specimens were prepared by placing a small amount of a sample on holey carbon-coated gold (Au) grids. Fast-Fourier transform (FFT) analyses were applied to various regions of the high resolution TEM (HRTEM) micrographs to investigate the crystal structure. Bright-field TEM (BF-TEM) micrographs and the corresponding selected-area electron diffraction (SAED) patterns were acquired to study the sample morphology and crystal structure. Energy dispersive spectroscopy (EDS) analyses were also performed to investigate the elemental compositions of the samples. High-angle annular 
dark-field scanning TEM (HAADF-STEM) analysis was used to verify the formation of $\mathrm{NiFeO}_{\mathrm{x}}$. Electron energy-loss spectroscopy (EELS) spectra were collected at $300 \mathrm{kV}$ in diffraction mode on a post-column filter. The optical properties of the powder samples were studied by diffusereflectance ultraviolet-visible (DR-UV-vis) spectroscopy with a JASCO model V-670 spectrophotometer equipped with an integrating sphere. The spectra were scanned from 1100 to $200 \mathrm{~nm}$ using halogen and deuterium lamps as light sources. Contributions from scattering were removed using the Kubelka-Munk function.

Electrochemical measurement: The electrochemical measurements of $\mathrm{NiFeO}_{\mathrm{x}} / \mathrm{NF}, \mathrm{NiO}_{\mathrm{x}} / \mathrm{NF}$, $\mathrm{FeO}_{\mathrm{x}} / \mathrm{NF}$ and bare NF were conducted in a three-electrode system connected to a Bio-Logic VMP3 electrochemical workstation. In all measurements, a $\mathrm{Pt}$ wire and a $\mathrm{Hg} / \mathrm{HgO}(1.0 \mathrm{M}$ $\mathrm{NaOH})$ were used as counter and reference electrodes, respectively. Various concentrations $(0.01$ - $1 \mathrm{M})$ of $\mathrm{KOH}$ and $\mathrm{NaOH}(99.99 \%$, Sigma-Aldrich) were used as electrolyte solutions. The linear sweep voltammograms (LSVs) were recorded at a scan rate of $-1 \mathrm{mV} \mathrm{s}^{-1}$. All potentials were measured with respect to $\mathrm{Hg} / \mathrm{HgO}$, which was kept at $298 \mathrm{~K}$, and reported on the $\mathrm{RHE}$ scale. All current-potential relations in this study were reported with $i R$ corrections. Solution resistances $R$ were measured by impedance spectroscopy (100 kHz, $10 \mathrm{mV}$ amplitude).

Photocatalytic measurement: $\mathrm{NiFeO}_{\mathrm{x}} / \mathrm{Ta}_{3} \mathrm{~N}_{5}$ samples were tested for photocatalytic OER in the presence $\mathrm{S}_{2} \mathrm{O}_{8}{ }^{2-}$ as an electron scavenger. In a typical experiment, $0.1 \mathrm{M} \mathrm{Na} \mathrm{S}_{2} \mathrm{O}_{8}$ was dissolved in $100 \mathrm{~mL} \mathrm{H} \mathrm{H}_{2} \mathrm{O}$ with various concentrations $(0.01-1.0 \mathrm{M})$ of $\mathrm{NaOH}$ or $\mathrm{KOH}$. Then, $50 \mathrm{mg}$ of $\mathrm{NiFeO}_{\mathrm{x}} / \mathrm{Ta}_{3} \mathrm{~N}_{5}$ was suspended in the corresponding solution and stirred for 10 min with a magnetic stirrer prior to the measurement. The photocatalytic reactions were carried out in a circulating batch reactor connected to a gas chromatograph (GC: Bruker 450 GC, TCD, Ar gas, molecular sieve 13X) equipped with a vacuum line. ${ }^{29}$ The temperature of the reactor was 
controlled with a water circulation system. It should be noted that the pressure influence of the batch reactor caused by the increased temperature was taken into consideration. Before irradiation, the reaction vessel was degassed several times to remove air. Then, 100 Torr Ar gas was introduced into the photocatalytic system. A Xe lamp (CERMAX PE300-BF, $300 \mathrm{~W}$ ) was used as a light source, and the irradiation wavelength was controlled with a combination of a cold mirror and a water filter $(350<\lambda<800 \mathrm{~nm})$. A cut-off filter (HOYA L 42) was used on the aforementioned light source $(420<\lambda<800 \mathrm{~nm})$. The light intensity was measured using a spectroradiometer (EKO, LS-100). The homogeneity of the solution during the reaction was maintained by agitation with a magnetic stirrer.

\section{RESULTS AND DISCUSSION}

\section{Characterization of $\mathrm{NiFeO}_{x}$ on $\mathrm{Ni}$ foam and $\mathrm{Ta}_{3} \mathrm{~N}_{5}$ powder}

Figure 1A shows a transmission electron microscopy (TEM) image of $\mathrm{NiFeO}_{\mathrm{x}}$, revealing a nanoflake-like morphology (see also Figures S1 and S2 for more images). The corresponding electron energy-loss spectroscopy (EELS) spectrum shown in Figure 1B confirms a uniform mixture of $\mathrm{Ni}$ and $\mathrm{Fe}$ in the product. Figure $1 \mathrm{C}$ shows a compiled X-ray diffraction (XRD) pattern of the as-prepared $\mathrm{NiFeO}_{\mathrm{x}}$ electrocatalyst. The XRD pattern exhibited the weak characteristic of layered double hydroxide material with crystallographic planes (003), (006), (009) and (110), in good agreement with the literature. ${ }^{30}$ The weak signals suggest that most of the oxides remained amorphous in nature. No extra characteristic peaks were detected from the patterns, indicating that there were no detectable impurities in the products.

The TEM and STEM images of $\mathrm{NiFeO} / \mathrm{Ta}_{3} \mathrm{~N}_{5}$ before and after photocatalytic reactions are shown in Figures S3 and S4. A large extent of the $\mathrm{Ta}_{3} \mathrm{~N}_{5}$ surface was covered with $\mathrm{NiFeO}_{\mathrm{x}}$ 
catalyst, which had a similar nanoflake morphology surrounded by amorphous phases. The corresponding EELS spectra in Figure S3D confirmed the presence of $\mathrm{NiFeO}_{\mathrm{x}}$ catalysts on the $\mathrm{Ta}_{3} \mathrm{~N}_{5}$ surface. Additionally, as observed in Figure $\mathrm{S} 4$, the $\mathrm{NiFeO}_{\mathrm{x}} / \mathrm{Ta}_{3} \mathrm{~N}_{5}$ catalyst did not show any significant differences after the photocatalytic reactions.

The XRD patterns of $\mathrm{Ta}_{3} \mathrm{~N}_{5}$ and $\mathrm{NiFeO}_{\mathrm{x}} / \mathrm{Ta}_{3} \mathrm{~N}_{5}$ are shown in Figure $\mathrm{S} 5$. The $\mathrm{d}$-spacings observed for the initial material correspond to $\mathrm{Ta}_{3} \mathrm{~N}_{5}$ with an orthorhombic structure $(\mathrm{Cmcm})$ as the major phase. ${ }^{16,28}$ Two additional smaller peaks at $2 \theta=29^{\circ}$ and $32.7^{\circ}$, ascribable to $\mathrm{TaON}$ phase, which originates from incomplete nitridation, were also observed. Upon hydrothermal treatment, there is no change in $\mathrm{Ta}_{3} \mathrm{~N}_{5}$ phase observed. Additionally, the $\mathrm{NiFeO}_{\mathrm{x}}$ phase in $\mathrm{NiFeO}_{\mathrm{x}} / \mathrm{Ta}_{3} \mathrm{~N}_{5}$ was not evident from the XRD pattern, consistent with the amorphous nature of $\mathrm{NiFeO}_{\mathrm{x}}$.

The chemical state of the $\mathrm{NiFeO}_{\mathrm{x}}$ catalyst was further refined by the XPS analysis (Figure S6). Figures $\mathrm{S} 6 \mathrm{~A}$ and $\mathrm{B}$ show the XPS spectra of $\mathrm{Ni} 2 \mathrm{p}$ and $\mathrm{Fe} 2 \mathrm{p}$ in the $\mathrm{NiFeO}_{\mathrm{x}}$ catalyst, respectively. All spectra of $\mathrm{Ni} 2 \mathrm{p}$ and Fe $2 \mathrm{p}$ showed two prominent peaks and satellites; typical XPS spectra of the transition metal $2 \mathrm{p}$ spectra. ${ }^{31}$ At the Ni core level, two peaks at 873.1 and $855.4 \mathrm{eV}$, and two satellites at 879.5 and $861.1 \mathrm{eV}$ were observed. These spectra are indicative of $\mathrm{Ni}(\mathrm{OH})_{2}$ or $\mathrm{NiOOH}$ with a $\mathrm{Ni} 2 \mathrm{p}_{3 / 2}$ binding energy close to $855.4 \mathrm{eV}$ and a $\mathrm{Ni} 2 \mathrm{p}_{1 / 2}$ binding energy close to $873 \mathrm{eV} \cdot{ }^{22,23,31-33}$ The presence of $\mathrm{NiO}$ can be ruled out because it is generally distinguished from the oxyhydroxides from a multiplet splitting of the $\mathrm{Ni} 2 \mathrm{p}_{3 / 2}$ core level at 855.4 and $853.7 \mathrm{eV} .^{22,23,31-33}$

The Fe $2 p$ core level spectra display peaks at 724.1 and $711.2 \mathrm{eV}$, which correspond to $2 \mathrm{p}_{3 / 2}$ and $2 \mathrm{p}_{1 / 2}$, respectively. ${ }^{22,23,31,34}$ These spectra are consistent with the binding energies of iron oxides and oxyhydroxides as previously reported. However, unlike those for the Ni $2 \mathrm{p}$ spectra, it 
was difficult to distinguish the Fe phases from the XPS spectra because the various iron oxides (e.g., $\mathrm{FeO}, \mathrm{Fe}_{2} \mathrm{O}_{3}$, and $\mathrm{Fe}_{3} \mathrm{O}_{4}$ ) and oxyhydroxides (e.g., $\mathrm{FeOOH}$ ) have similar $\mathrm{Fe} 2 \mathrm{p}$ core levels and peak shapes. ${ }^{23,31,34}$ The XPS spectra of O 1s (Figure S6C) exhibited one broad peak centered at $530.3 \mathrm{eV}$, which is assigned to adventitious oxygen species.

The Ni $2 p$ and Fe $2 p$ core level spectra of $\mathrm{NiFeO}_{\mathrm{x}} / \mathrm{Ta}_{3} \mathrm{~N}_{5}$ (Figures $\mathrm{S} 6 \mathrm{~A}$ and $\mathrm{B}$ ) confirmed the existence of $\mathrm{NiFeO}_{x}$ catalysts on the $\mathrm{Ta}_{3} \mathrm{~N}_{5}$ surface. The peaks positions after the photocatalytic reaction did not show significant differences when compared with those observed in the $\mathrm{NiFeO}_{\mathrm{x}}$ catalyst. This suggests a similar oxidation state of the $\mathrm{NiFeO}_{\mathrm{x}}$ present on the outer surface as prepared. The Ta $4 \mathrm{f}$ core level spectra of $\mathrm{NiFeO}_{\mathrm{x}} / \mathrm{Ta}_{3} \mathrm{~N}_{5}$ before and after the photocatalytic reaction are compared in Figure S6E. The XPS spectra of Ta $4 \mathrm{f}$ exhibited two peak maxima at binding energies of $24.7 \mathrm{eV}$ for $\mathrm{Ta} 4 \mathrm{f}_{7 / 2}$ and $26.7 \mathrm{eV}$ for $\mathrm{Ta} 4 \mathrm{f}_{5 / 2}$, which are characteristic for $\mathrm{Ta}_{3} \mathrm{~N}_{5}{ }^{16}$ Figure S6F displays two peaks at 403.5 and $396 \mathrm{eV}$ attributed to the Ta $4 \mathrm{p}_{3 / 2}$ and N $1 \mathrm{~s}$ of the metal nitride $(\mathrm{Ta}-\mathrm{N})$, respectively. ${ }^{16}$

The DR UV-Vis spectra in the Kubelka-Munk function of the $\mathrm{Ta}_{3} \mathrm{~N}_{5}$ and $\mathrm{NiFeO}_{\mathrm{x}} / \mathrm{Ta}_{3} \mathrm{~N}_{5}$ samples are shown in Figure S7. Both samples had band edge absorption at approximately 600 $\mathrm{nm}$, which are attributable to electron transitions from the $\mathrm{N} 2 \mathrm{p}$ orbitals to the empty Ta $5 \mathrm{~d}$ orbitals. $^{16,19,28}$

\section{Electrochemical investigation of $\mathrm{NiFeO}_{x}$}

The electrochemical OER performance of the prepared $\mathrm{NiFeO}_{\mathrm{x}}$ supported on $\mathrm{NF}$ was investigated. Figure 2 compiles LSVs for the OER over $\mathrm{NiFeO}_{x} / \mathrm{NF}$ in various alkaline electrolyte solutions. As a reference, polarization curves over a bare NF are also depicted. In all cases, the current densities monotonically increased with applied potential. In both $\mathrm{NaOH}$ and 
$\mathrm{KOH}$ electrolytes, $\mathrm{NiFeO}_{\mathrm{x}}$ showed significantly higher current densities than the bare NF, consistent with the literature. ${ }^{22,24,35-39}$ Additionally, larger current densities were observed in denser solutions, most likely due to a positive kinetic order in hydroxide ions for the OER. ${ }^{24}$ Importantly, the $\mathrm{NiO}_{\mathrm{x}} / \mathrm{NF}$ catalyst showed an improved performance over the bare NF (Figure S8). However, the OER performance of the $\mathrm{NiFeO}_{\mathrm{x}} / \mathrm{NF}$ catalyst was much superior to that of the $\mathrm{NiO}_{\mathrm{x}} / \mathrm{NF}$ catalyst (Figure S8), consistent with the involvement of Fe species in the catalytic cycle as reported. ${ }^{40,41}$ Figure S9 shows a small Tafel slope of approximately $40 \mathrm{mV} \mathrm{dec}{ }^{-1}$ over the $\mathrm{NiFeO}_{\mathrm{x}} / \mathrm{NF}$ catalyst, consistent with the literature. ${ }^{36}$

The OER was further investigated electrochemically at various temperatures. Figure 3A compiles Tafel analyses of the OER at $279,300,325$ and $346 \mathrm{~K}$ in $1.0 \mathrm{M} \mathrm{NaOH}$. At these temperatures, the currents increased with the applied potential. Clear linear relationships between the current densities on the logarithmic scale and the potentials were observed for all temperature regimes; however, a slight decrease in the Tafel slope with temperature was observed (see also Figures S10 and S11). From the experimental current-potential relationship in Figure 3A, the value of a current at zero-overpotential $i_{0}\left(E=1.23 \mathrm{~V}\right.$ vs. RHE) was extracted. The obtained $i_{0}$ is compiled against temperature as shown in Figure 3B. In the form of Arrhenius plot, the following relation:

$$
\frac{d \ln \left(i_{0}\right)}{d(1 / T)}=-\frac{E_{a, a p p}}{R},
$$

is empirically well confirmed, where $E_{a, a p p}$ is the apparent activation energy, $R$ is the gas constant and $T$ is the absolute temperature. From the slope obtained in Figure 3B, the activation energy was calculated with Equation 1. The obtained activation energy in our system was found to be $25 \pm 12 \mathrm{~kJ} \mathrm{~mol}^{-1}$ (See also the supporting information for further discussions on the activation energy). Although we were unable to locate any data in the literature on the activation 
energy for OERs using $\mathrm{NiFeO}_{\mathrm{x}}$, several values were reported in alkaline environments for other materials, e.g., $\mathrm{Ni}^{42} 75 \mathrm{~kJ} \mathrm{~mol}^{-1}$ and $\mathrm{NiCoO}_{\mathrm{x}}:{ }^{43} 71 \mathrm{~kJ} \mathrm{~mol}^{-1}$. The activation energy of $\mathrm{NiFeO}_{\mathrm{x}}$ was much smaller than the other aforementioned materials reported in the literature and was consistent with the higher OER performance over $\mathrm{NiFeO}_{\mathrm{x}}$ in Figures 2 and S8. Further detailed discussions can be found in the supporting information regarding the derivation of the rate expression.

\section{Photocatalytic investigation of $\mathrm{NiFeO}_{\mathrm{x}}$}

The $\mathrm{NiFeO}_{\mathrm{x}}$ catalyst was immobilized on the surface of $\mathrm{Ta}_{3} \mathrm{~N}_{5}$ by a hydrothermal method that was similar to the method of deposition on NF. Upon successful dispersion (see Figures S3 and S4 for the TEM images, Figure S5 for the XRD patterns, Figure S6 for the XPS spectra, and Figure S7 for the UV-Vis spectra), the photocatalytic activity of $\mathrm{NiFeO}_{\mathrm{x}} / \mathrm{Ta}_{3} \mathrm{~N}_{5}$ was tested for the OER using $\mathrm{Na}_{2} \mathrm{~S}_{2} \mathrm{O}_{8}$ as an electron scavenger. The photocatalytic OER activities of $\mathrm{NiFeO}_{\mathrm{x}} / \mathrm{Ta}_{3} \mathrm{~N}_{5}$ were first tested with different $\mathrm{NiFeO}_{\mathrm{x}}$ loadings and compared with the bare $\mathrm{Ta}_{3} \mathrm{~N}_{5}$; the results are shown in Figure S12 (see also Table S1 for the ICP analysis). The OER rate improved from 100 to $200 \mu \mathrm{mol} \mathrm{h}{ }^{-1}$ with increasing $\mathrm{NiFeO}_{\mathrm{x}}$ loading from 0.7 to $2.2 \mathrm{wt} \%$, achieving QE up to $24 \%$ at $480 \mathrm{~nm}$ (see Figure S13 for full action spectra). Also, the $\mathrm{NiFeO}_{\mathrm{x}} / \mathrm{Ta}_{3} \mathrm{~N}_{5}$ showed a stable performance for longer than $15 \mathrm{~h}$ (Figure S14). Further increasing the $\mathrm{NiFeO}_{\mathrm{x}}$ loading to $2.8 \mathrm{wt} \%$ did not improve the OER rate but instead significantly reduced the rate to $50 \mu \mathrm{mol} \mathrm{h}$. This behavior has generally been observed in the powder system due to the competitive light absorption by the semiconductor photocatalysts and the cocatalysts, and the requirement of both reduction and oxidation sites. ${ }^{14,44-47} \mathrm{Ta}_{3} \mathrm{~N}_{5}$ treated in the same hydrothermal condition (without loading $\mathrm{NiFeO}_{\mathrm{x}}$ ) gave similar photocatalytic performance compared to the 
non-treated $\mathrm{Ta}_{3} \mathrm{~N}_{5}$, suggesting that the improvement of photocatalytic activity was not due to the hydrothermal treatment of $\mathrm{Ta}_{3} \mathrm{~N}_{5}$, but to the presence of $\mathrm{NiFeO}_{\mathrm{x}}$ catalyst decorated onto $\mathrm{Ta}_{3} \mathrm{~N}_{5}$. The photocatalytic activity of $\mathrm{Ta}_{3} \mathrm{~N}_{5}$ after hydrothermal treatment remained low in the absence of $\mathrm{NiFeO}_{\mathrm{x}}$ catalyst (Figure S15).

It is well-known that the photocatalytic OER proceeds more efficiently under alkaline conditions; however, the effects of hydroxide ion concentration have not been thoroughly investigated. $^{48,49}$ Hence, in line with the electrochemical study, we examined the effects of hydroxide ion concentration on the photocatalytic OER over $2.1 \mathrm{wt} \% \mathrm{NiFeO}_{\mathrm{x}} / \mathrm{Ta}_{3} \mathrm{~N}_{5}$. The photocatalytic OER was studied in $\mathrm{KOH}$ and $\mathrm{NaOH}$ for hydroxide ion concentrations of $0.01 \mathrm{M}$, $0.1 \mathrm{M}$, and $1 \mathrm{M}$, and the results are shown in Figure 4. The OER rate was slightly increased with increasing hydroxide ion concentration from $0.01 \mathrm{M}$ to $0.1 \mathrm{M}$ for both $\mathrm{NaOH}$ (Figure 4A) and $\mathrm{KOH}$ (Figure 4B). Further improvement was observed when the hydroxide ion concentration reached $1 \mathrm{M}$. However, the comparison of $\mathrm{pH}$ effects (i.e., hydroxide ion concentration effect) on the OER in the electrochemical study (Figure 2) with those in the photocatalytic activity study (Figure 4) is not straightforward because a few of the intrinsic properties of the $\mathrm{Ta}_{3} \mathrm{~N}_{5}$ semiconductor are known to be directly affected by the $\mathrm{pH}$ change. Oxide semiconductors have been shown to tend to undergo flatband potential $\left(E_{F B}\right)$ changes at different $\mathrm{pH}$ due to Helmholtz layer $\left(V_{H}\right)$ alterations at the semiconductor-electrolyte interface. Generally, the $\mathrm{pH}$ change will introduce a flatband position shift with respect to the redox potentials in the electrolyte. ${ }^{50}$ In the case of nitride material, this effect has not been well investigated. Our experimental results at $\mathrm{pH}$ 12 and 13.5 found an approximately $0.2 \mathrm{~V}$ difference in the $E_{F B}$ for $\mathrm{Ta}_{3} \mathrm{~N}_{5}$ as shown in Figure S16. This finding is in accordance with the literature where the $E_{F B}$ change at different $\mathrm{pH}$ was observed for $\mathrm{GaN}$ and $\mathrm{Ta}_{3} \mathrm{~N}_{5}$ but to a different extent. ${ }^{9,51}$ Nevertheless, the fact that the $E_{F B}$ on 
the SHE scale changed with $\mathrm{pH}$ did not necessarily indicate a potential for the $\mathrm{Ta}_{3} \mathrm{~N}_{5}$ photocatalyst to drive the OER increases. According to the Nernst equation, the reduction and oxidation standard potentials of water on the SHE scale also depend on the $\mathrm{pH}$. If we carefully compare these values, the $\mathrm{pH}$ dependence of the $E_{F B}$ shift was approximately $-133 \mathrm{mV} \mathrm{pH}^{-1}$, whereas the shift in the OER standard potential was $-59 \mathrm{mV} \mathrm{pH}^{-1}$ on the SHE scale. These values could indicate that if the change in the $E_{F B}$ had a significant impact on the OER, then denser hydroxide solutions would provide smaller driving forces for the OER and result in a lower reaction rate. However, this contradicts the experimental observations: hence, it is unlikely that the observed improvement of the photocatalytic OER was due to the $E_{F B}$ change. Therefore, we can alternatively assign the improvement of the photocatalytic OER rate to the enhanced surface OER as observed from the electrochemical study (Figure 2).

The effect of light intensity on the photocatalytic OER activity was examined from 4 to $20 \times$ $10^{22}$ photon $\mathrm{h}^{-1}$, and the results are shown in Figure 5. The OER rate increased as the light intensity increased, but no linear relationship was observed (approximately 0.66 order dependence). Generally, a linear relationship between the reaction rate and the light intensity in photocatalytic reaction is observed in lower light intensity regions below $1 \times 10^{22}$ photon $\mathrm{h}^{-1}$. At higher intensity regions, the photocatalytic reaction rate is typically proportional to the square root of the light intensity. ${ }^{44,46,47}$ The observed non-linear behavior of the photocatalytic reaction rate with respect to the light intensity was likely due to the accumulation of electrons and holes on the surface prior to the redox reaction on the cocatalyst. The photocatalytic OER rate-light intensity relation mechanism will be further discussed later in detail.

A further photocatalytic study was conducted at different temperatures to investigate the apparent activation energy. Unlike ordinary chemical reactions, the activation energy for a 
photocatalytic reaction is not simply associated with the rate constant of the rate determining step (rds). In our study, we employed $\mathrm{Na}_{2} \mathrm{~S}_{2} \mathrm{O}_{8}$ as a strong electron scavenger to accelerate the electron consumption process, which in turn will make the OER as the kinetically relevant step. Hence, we attempted to apply a similar concept of rds to our photocatalytic system. The photocatalytic OER activity was studied at different temperatures from $275 \mathrm{~K}$ to $348 \mathrm{~K}$ in $1 \mathrm{M}$ $\mathrm{NaOH}$. As depicted in Figure 6, the photocatalytic OER activity increased with increasing temperature. The activation energy was calculated from the Arrhenius plot and found to be 16 $\pm 1.5 \mathrm{~kJ} \mathrm{~mol}^{-1}$. This value is in the range of reported activation energies for the photocatalytic overall water splitting reaction or the photocatalytic OER in the presence of electron scavenger. For instance, the activation energy for the OER over $\mathrm{Rh}_{2-\mathrm{y}}-\mathrm{Cr}_{\mathrm{y}} \mathrm{O}_{3} /\left(\mathrm{Ga}_{1-\mathrm{x}} \mathrm{Zn}_{\mathrm{x}}\right)\left(\mathrm{N}_{1-\mathrm{x}} \mathrm{O}_{\mathrm{x}}\right)$ was reported to be $9 \mathrm{~kJ} \mathrm{~mol}^{-1} \cdot{ }^{24,46,47}$ Similarly, for overall water splitting, an activation energy of $8 \mathrm{~kJ}$ $\mathrm{mol}^{-1}$ was reported for $\left(\mathrm{Ga}_{1-\mathrm{x}} \mathrm{Zn}_{\mathrm{x}}\right)\left(\mathrm{N}_{1-\mathrm{x}} \mathrm{O}_{\mathrm{x}}\right)$ loaded with a $\mathrm{Rh}_{2-\mathrm{y}}-\mathrm{Cr}_{\mathrm{y}} \mathrm{O}_{3}$ cocatalyst and $15 \mathrm{~kJ} \mathrm{~mol}^{-1}$ when loaded with a Ni cocatalyst. ${ }^{24,46,47}$

\section{Comparison between electrochemical and photocatalytic OER}

The OER was separately investigated in electrochemical and photocatalytic systems. The electrochemical investigation revealed an apparent activation energy of $25 \mathrm{~kJ} \mathrm{~mol}^{-1}$, whereas that of the photocatalytic OER with an electron scavenger was $16 \mathrm{~kJ} \mathrm{~mol}^{-1}$. The difference between these values will be compared hereafter. As an initial attempt, the photocatalytic OER rate equation was derived from the consumption (reaction/recombination) and transport (migration/diffusion) of photoexcited charges (see Figure S17 for the detail scheme of photoexcited carriers kinetics). ${ }^{25}$ The reaction can be expressed as:

$$
v_{\text {react }}=\sqrt{\frac{K_{e} K_{h 2} k_{O} k_{\text {red. }} \alpha I}{k_{r}}},
$$


where $v_{\text {react }}$ is the overall rate of the photocatalytic reduction and oxidation reactions (i.e., in this case: $\mathrm{S}_{2} \mathrm{O}_{8}{ }^{2-}$ reduction and OER, respectively); $k_{h 1}, k^{\prime}{ }_{h 1}, k_{h 2}, k_{h 2}^{\prime}, k_{O}, k_{e}, k_{e}^{\prime}$, and $k_{r e d}$ are the rate constants for corresponding photoexcited carriers; $\alpha$ is the absorption coefficient of the semiconductor; and $I$ is the incident light intensity. This equation applies when the light intensity is large and when $\left[\mathrm{e}_{d a r k}^{-}\right]$and $k_{r}$ are small, which is the case in our study as described in the photocatalysis section (see the supporting information for the detailed derivation). Under such conditions, the overall rate of the photocatalytic OER is proportional to square root of the equilibrium constant of the electrons between the surface and bulk, the equilibrium constant of the holes between the surface and cocatalyst, the OER constant, the reduction rate constant, the absorption coefficient of the material, the light intensity and the inverse of the recombination reaction rate. According to Equation 2, the overall activation energy for the photocatalytic OER can be smaller than that for the electrochemical OER when the summation of the involved rate constants other than $k_{O}$ are larger (smaller $E_{a}$ ) than $k_{O}$ and the equilibrium constants are smaller (smaller $\Delta G$ ), i.e., $\left\{\Delta G_{e}+\Delta G_{h 2}+E_{\text {red. }}+\exp (\alpha I)-\Delta G_{r}\right\}<E_{O}$. Notably, the apparent $k_{O}$ is potential dependent in the photocatalytic system. In terms of electrochemistry, usually the activation energy without overpotential isolation decreases with the overpotential (see the supporting information for more details)). Nevertheless, even if such is the case, the other involved activation energy and Gibbs free energy terms have to be small enough to have a smaller apparent activation energy in the photocatalytic OER than that of the electrochemical OER. Therefore, the obtained smaller apparent activation energy in the photocatalytic OER still indicates the surface reaction dominates the overall reaction rate expression.

Other temperature dependent terms have to be addressed to effectively compare the two systems. When the photocatalytic reaction was varied by changing the temperature, a few of the 
intrinsic properties of the $\mathrm{Ta}_{3} \mathrm{~N}_{5}$ semiconductor are anticipated to change. The relationship between temperature and bandgap energy is described by the Varshni equation shown below: ${ }^{52}$

$$
E_{g}(T)=E_{g}(0)-\frac{\alpha_{E} T^{2}}{T+\beta_{E}}
$$

where $E_{g}(0)$ is the bandgap energy at absolute zero on the Kelvin scale of the given material, and $\alpha_{E}$ and $\beta_{E}$ are material-specific constants that are generally in the range of $10^{-4}$ and $200-600$, respectively. Considering that the temperature change in our experiment is only from 275 to 348 $\mathrm{K}$, the bandgap energy change is negligible (ca. $0.01 \mathrm{eV}$ ).

In photocatalytic reactions, carrier density is related to carrier transport and affects the conductivity and degree of band bending. The carrier density is in a function of the effective density of states in the appropriate band (i.e., conduction for n-type, valence for p-type), the Fermi level in the material (which is a function of temperature and dopant concentrations), and the temperature as given by the following equations: ${ }^{.52}$

$$
\begin{aligned}
& n=N_{C} \exp \left(\frac{E_{F}-E_{C}}{k_{B} T}\right) \text { with } N_{C}=2\left(\frac{2 \pi m_{e}^{*} k_{B} T}{h^{2}}\right)^{\frac{3}{2}}, \\
& p=N_{V} \exp \left(\frac{E_{V}-E_{F}}{k_{B} T}\right) \text { with } N_{V}=2\left(\frac{2 \pi m_{h}^{*} k_{B} T}{h^{2}}\right)^{\frac{3}{2}},
\end{aligned}
$$

where $n$ is the electron density, $p$ is the hole density, $N_{C}$ is the density of states in the conduction band, $N_{V}$ is the density of states in the valence band, $E_{C}$ is the conduction band energy level, $E_{V}$ is the valence band energy level, $E_{F}$ is the Fermi energy level, $k_{B}$ is the Boltzmann constant, and $T$ is temperature. The temperature dependence of the carrier density in a doped semiconductor (like that in $\mathrm{Ta}_{3} \mathrm{~N}_{5}$ ) generally results in three different behaviors for different temperature ranges (i.e., ionization, extrinsic, and intrinsic). At low temperatures $(T<100 \mathrm{~K})$, the carrier 
concentration is low, and the donor electrons are bound to the donor atoms. At $100 \mathrm{~K}$, the ionization region forms, and the carrier concentration is solely determined by doping because all atoms are ionized. In this region, there is only enough latent energy in the material to push a few of the dopant carriers into the conduction band. As the temperature increases to the extrinsic region $(100 \mathrm{~K}<T<400 \mathrm{~K})$, all dopant carriers are energized into the conduction band, and there is very little thermal generation of additional carriers. In this region, an increase in temperature produces no increase in carrier concentration. At higher temperatures $(T>400 \mathrm{~K})$ the carrier concentration increases with temperature because the number of thermally generated carriers exceeds the dopant carrier. In the temperature range where our experiment was conducted (i.e., $275-348 \mathrm{~K}$ ), the change in carrier density was negligible according to the extrinsic region.

Carrier mobility is an important parameter in photocatalytic reactions. It is proportional to the diffusion coefficient of the carrier that affects the diffusion current in a semiconductor photocatalyst. $^{53,54}$ The effect of temperature on carrier mobility is related to impurity scattering and phonon scattering. Impurity scattering is influenced by the presence of charged impurities, such as those originating from crystal defects. Increasing the temperature will increase the lattice vibration and thereby limit the carrier mobility. The carrier mobility is limited by phonon scattering as the temperature change by approximately $\mathrm{T}^{-3 / 2} \cdot{ }^{52}$ On the other hand, the impurity scattering decreases as the temperature increases; this increases the mobility by a factor of approximately $\mathrm{T}^{3 / 2}$. However, the effect of impurity scattering is often observed only at very low temperatures. A direct correlation between the carrier mobility and temperature is generally expressed by an empirical formula obtained from experimental results. In this regard, the temperature dependence of the carrier mobility is also affected by the carrier density, where a significant carrier mobility decrease is often observed for a low carrier density semiconductor 
(approximately $10^{-17} \mathrm{~cm}^{-3}$ ). Due to the lack of information on the empirical formula for carrier mobility as a function of temperature, we estimated the carrier mobility change as shown in Figure S18. Under our experimental conditions, the carrier mobility change with increasing temperature was expected to be negligible.

As has been discussed, all the critical parameters associated with the semiconductor properties (i.e., bandgap, carrier density and carrier mobility) were found to be most likely unaltered within the studied temperature regime. Apart from the semiconductor properties, there are several aspects that are influenced by the system temperature.

First, the Gibbs free energy of water splitting was altered by the reaction temperature. Figure S19 shows the calculated changes in the Gibbs free energy and the corresponding reversible voltages with temperature. ${ }^{55}$ A reduction of the reversible potential by approximately $50 \mathrm{mV}$ was observed when the temperature increased from $298 \mathrm{~K}$ to $353 \mathrm{~K}$. Notably, the potential of the working electrode during the electrochemical study was measured against the reference electrode, which was kept at $298 \mathrm{~K}$. The decrease in the reversible voltage improved the apparent photocatalytic processes at elevated temperatures (due to a larger overvoltage at higher temperature).

The temperature in the water splitting system has a major influence on the mass transport in the electrolyte. As the reaction rate increases, the diffusion becomes problematic. If we simply consider the Fick's law in conjunction with the Nernst-type diffusion, the following equation is obtained:

$$
J=-D \frac{\partial c}{\partial x}=-D \frac{c_{b}}{x}
$$

where $D$ is the diffusion coefficient, $c_{b}$ is the concentration at the bulk of electrolyte and $x$ is the diffusion layer thickness. When this equation is applied to hydroxide ion diffusion with $D_{\mathrm{OH}^{-}}=$ 
$5.27 \times 10^{-5} \mathrm{~cm}^{2} \mathrm{~s}^{-1},{ }^{55} x=0.05 \mathrm{~cm}$ (typical value in unstirred system) and $c_{b}=1.0 \times 10^{-3} \mathrm{~mol}$ $\mathrm{cm}^{-3}$, the hydroxide ion flux was calculated to be approximately $100 \mathrm{~mA} \mathrm{~cm}^{-2}$ at $298 \mathrm{~K}$. Of note, the surface area in the unit corresponds to the actual surface area rather than the geometric surface area. The mass transport also varies with temperature due to the temperature dependence of the diffusion coefficient. The following equation (Stokes-Einstein equation) provides a theoretical description of the diffusion coefficient: ${ }^{56}$

$$
D=\frac{k T}{6 \pi a \mu}
$$

where $k$ is Boltzmann's constant and $a$ represents the ion radius. The equation indicates that the diffusion coefficient proportionally increases with temperature. Furthermore, the viscosity of the solution $\mu$ decreases with temperature, which in turn further increases the diffusion coefficient. At a substantial reaction rate, the increase in mass transport may enhance the apparent reaction rate if the mass transport flux is significantly smaller than the reaction rate. Under such conditions, the measured apparent activation energy becomes smaller than the true apparent activation energy. In our photocatalytic system, no stirring rate influence was empirically confirmed, excluding such possibility.

One of the most critical parameters that significantly influences the aqueous phase electrochemical process efficiency is the solution resistance. ${ }^{57}$ Because the surface electrochemical redox reaction proceeds during the photocatalytic process, this aspect seems more or less problematic for the photocatalytic reaction as well. According to the Stokes model, the solution resistance can be theoretically described as follows: ${ }^{56,58,59}$

$$
R=K_{\text {cell }} \frac{6 \pi \mu a}{z^{2} e c F}
$$


where $K_{\text {cell }}$ is the cell constant; $v$ denotes the solution viscosity; $a$ represents the effective sizes of the ion; $z$ is the valence of the ion; $c$ represents the solute concentration; $e$ is the elementary charge and $F$ is Faraday's constant. The measured relative solution resistance was plotted against temperature in Figure S20. The figure shows drastically decreasing solution resistances with temperature. At $348 \mathrm{~K}$, the solution resistance of $1.0 \mathrm{M} \mathrm{NaOH}$ was approximately $80 \%$ of that at $298 \mathrm{~K}$. Although the solution resistance is not directly in a function of temperature, the included parameters, such as the viscosity of the electrolyte solution, are temperature dependent. Figure S20 also compiles the relative viscosity of a sodium hydroxide solution. ${ }^{60}$ The viscosity more significantly decreases with temperature than the measured solution resistance, implying the existence of other parameters that depend on temperature. Because the solution resistance was empirically measured at working conditions, higher reaction rates at elevated temperatures likely induced more bubble formation on the surface. The formed bubbles at high reaction rates are known to increase the solution resistance. ${ }^{61,62}$ Overall, the reduction in the solution resistance with increasing temperature will certainly improve the apparent reaction rate at a given potential, due to a smaller $i R$ drop in the system.

Another factor that affects the aqueous phase gas evolution reaction and changes with temperature is the solubility of gases. Gas solubility is associated with the size of bubbles formed during water electrolysis, which alters the solution resistance. ${ }^{57,61}$ The following equation (Sechenov equation) has been empirically confirmed for describing the gas solubility in the electrolyte solution: ${ }^{62}$

$$
\log \left(\frac{c_{G, 0}}{c_{G}}\right)=K c_{s},
$$


where $c_{G, 0}$ and $c_{G}$ are the gas solubilities in pure water and in the electrolyte, respectively; $K$ is the Sechenov constant, which depends on the salt, the gas and the temperature; and $c_{s}$ is the salt concentration. The Sechenov equation was later extended by Schumpe: ${ }^{62}$

$$
\log \left(\frac{c_{G, 0}}{c_{G}}\right)=\sum\left(h_{i}+h_{G, 0}\right) c_{i},
$$

where $h_{i}$ and $h_{G, 0}$ represent the ion and gas specific constants, respectively. With respect to the temperature dependent solubility, Schumpe further extended the relation with the following modified gas specific parameter:

$$
h_{G}=h_{G, 0}+h_{T}\left(T-T_{0}\right)
$$

where $h_{G}$ is the gas specific parameter at the temperature of $T, h_{T}$ is the parameter describing temperature dependence of gas specific parameter, and $T_{0}$ is the standard temperature (298.15 K). ${ }^{63}$ These equations were adopted to our system $\left(1.0 \mathrm{~mol} \mathrm{~L}{ }^{-1} \mathrm{NaOH}\right.$ and $\left.279 \mathrm{~K}<T<346 \mathrm{~K}\right)$ with $h_{i}\left(\mathrm{Na}^{+}\right)=0.1143, h_{i}\left(\mathrm{OH}^{-}\right)=0.0839, h_{G, 0}\left(\mathrm{O}_{2}\right)=0$ and $h_{T}\left(\mathrm{O}_{2}\right)=-0.334 \times 10^{-3} \mathrm{~m}^{3} \mathrm{kmol}^{-1}$. The calculated oxygen solubility is plotted against temperature in Figure S21. As expected from the negative $h_{T}$, the oxygen solubility was observed to increase with temperature. The increase in the solubility induces fewer bubble formation, which in turn reduces the solution resistance locally. ${ }^{61}$ Therefore, regarding the solution resistance, a higher temperature provides a less viscous solution and a larger gas solubility, which reduces the solution resistance. However, the resultant smaller solution resistance leads to a higher reaction rate, which causes the formation of more bubbles on the surface and increases the solution resistance to some extent.

In summary, this section compared the obtained activation energies in the electrochemical and photocatalytic OER. Our detailed discussion revealed that all critical parameters associated with the semiconductor properties (i.e., bandgap, carrier density and carrier mobility) were likely 
unaltered in the studied temperature regime. Thus, the acquired smaller apparent activation energy in the photocatalytic OER likely implies that the surface OER was the bottle-neck process during the photocatalytic OER. However, our detailed discussion also disclosed the importance of isolating the altered parameters with temperature in a photocatalytic system, such as ion migration (solution resistance) and surface potential.

\section{CONCLUSIONS}

This study elucidates the impact of solute and temperature on electrocatalysis (on NF) and photocatalysis (on $\mathrm{Ta}_{3} \mathrm{~N}_{5}$ with $\mathrm{Na}_{2} \mathrm{~S}_{2} \mathrm{O}_{8}$ as an electron scavenger) using the common $\mathrm{NiFeO}_{\mathrm{x}}$ catalyst. The $\mathrm{NiFeO}_{\mathrm{x}} / \mathrm{Ta}_{3} \mathrm{~N}_{5}$ photocatalyst showed a quantum efficiency greater than $20 \%$ in the visible range. The rates increased in more alkaline conditions $(0.01-1.0 \mathrm{M}$ hydroxide ion $)$ for both electrocatalysis and photocatalysis, suggesting that the OER at the $\mathrm{Ta}_{3} \mathrm{~N}_{5}$ surface predominantly determined the overall photocatalytic rates under the investigated conditions. Activation energies of approximately 25 and $16 \mathrm{~kJ} \mathrm{~mol}^{-1}$ were found for the electrocatalytic and photocatalytic OER, respectively. The lower temperature dependence (smaller apparent activation energy) in the photocatalysis relative to the electrocatalytic half reaction was associated with the other involved steps. The changes in the photophysical properties (e.g., bandgap, Fermi energy, and carrier density) were nearly insensitive to temperature in our studied conditions. However, electron/hole migration and diffusion were found to be kinetically faster than the surface redox reactions. Because the rate constant for electrochemical reaction is potential dependent, the activation energy is dependent on the operating potential for steady state photocatalysis. This fact indicates that the apparent activation energy of photocatalysis appears to be smaller than that for the electrochemical half reaction where the overpotential term is 
effectively excluded. Additionally, temperature alters ion migration in the liquid phase (solution resistance); however, the short distance over which the redox reactions occur on the photocatalyst surface may minimize these effects. Our present report provides an effective strategy to investigate the degrees of contribution of the surface redox reaction during photocatalytic process to the overall reaction rates. Such a careful investigation can pin down the direction of our research effort, which leads to photocatalysis by design concept toward efficient solar fuel production.

\author{
ASSOCIATED CONTENT \\ Supporting Information. Additional experimental details and characterization data are \\ supplied in Supporting Information. This material is available free of charge via the Internet at \\ http://pubs.acs.org.
}

\title{
AUTHOR INFORMATION
}

\section{Corresponding Author}

*E-mail: kazuhiro.takanabe@kaust.edu.sa

Website: http://catec.kaust.edu.sa

Tel: (Office) +966 128084485

\section{Author Contributions}


The manuscript was written with contributions from all authors. All authors have given approval to the final version of the manuscript.

\section{ACKNOWLEDGMENT}

The research reported in this publication was supported by the King Abdullah University of Science and Technology (KAUST). The authors would like to thank Dr. Dalaver H. Anjum and Ms. Aya Saidi for their help with TEM and electrochemical measurements, respectively.

\section{REFERENCES}

(1) Takanabe, K.; Domen, K. Green 2011, 1, 313-322.

(2) Hisatomi, T.; Kubota, J.; Domen, K. Chem. Soc. Rev. 2014, 43, 7520-7535.

(3) Walter, M. G.; Warren, E. L.; McKone, J. R.; Boettcher, S. W.; Mi, Q.; Santori, E. A.; Lewis, N. S. Chem. Rev. 2010, 110, 6446-6473.

(4) Maeda, K.; Domen, K. J. Phys. Chem. Lett. 2010, 1, 2655-2661.

(5) Pinaud, B. A.; Benck, J. D.; Seitz, L. C.; Forman, A. J.; Chen, Z.; Deutsch, T. G.; James, B. D.; Baum, K. N.; Baum, G. N.; Ardo, S.; Wang, H.; Miller, E.; Jaramillo, T. F. Energy Environ. Sci. 2013, 6, 1983-2002.

(6) Kudo, A.; Miseki, Y. Chem. Soc. Rev. 2009, 38, 253-278.

(7) Kamat, P. V.; Meisel, D. C. R. Chimie, 2003, 6, 999-1007. 
(8) Yoshida, M.; Yamakata, A.; Takanabe, K.; Kubota, J.; Osawa, M.; Domen, K. J. Am. Chem. Soc. 2009, 131, 13218-13219.

(9) Chun, W.; Ishikawa, A.; Fujisawa, H.; Takata, T.; Kondo, J. N.; Hara, M.; Kawai, M.; Matsumoto, Y.; Domen, K. J. Phys. Chem. 2003, 107, 1798-1803.

(10) Hitoki, G.; Ishikawa, A.; Takata, T.; Kondo, J. N.; Hara, M.; Domen, K. Chem. Lett. 2002, 736-737.

(11) Ishikawa, A.; Takata, T.; Kondo, J. N.; Hara, M.; Domen, K. J. Phys. Chem. 2004, 108, 11049-11053.

(12) Liu, G.; Shi, L.; Zhang, F.; Chen, Z.; Han, J.; Ding, C.; Chen, S.; Wang, Z.; Han, H.; Li, C. Angew. Chem. Int. Ed. 2014, 53, 7295-7299.

(13) Zhang, P.; Zhang, J.; Gong, J. Chem. Soc. Rev. 2014, 43, 4395-4422.

(14) Garcia-Esparza, A. T.; Takanabe, K. J. Mater. Chem. A 2016 DOI: 10.1039/C5TA06983A

(15) Ziani, A.; Nurlaela, E.; Dhawale, D. S.; Silva, D. A.; Alarousu, E.; Mohammed, O. F.; Takanabe, K. Phys. Chem. Chem. Phys. 2015, 17, 2670-2677.

(16) Nurlaela, E.; Ould-Chikh, S.; Harb, M.; del Gobbo, S.; Aouine, M.; Puzenat, E.; Sautet, P.; Domen, K.; Basset, J.; Takanabe, K. Chem. Mater. 2014, 26, 4812-4825.

(17) Liu, X.; Zhao, L.; Domen, K.; Takanabe, K. Mater. Res. Bull. 2014, 49, 58-65.

(18) Ohnishi, R.; Katayama, M.; Cha, D.; Takanabe, K.; Kubota, J.; Domen K. J. Electrochem. Soc. 2013, 160, F501-F506. 
(19) Su Su Khine Ma, Hisatomi, T,; Maeda, K.; Moriya, Y.; Domen, K. J. Am. Chem. Soc. 2012, 134, 19993-19996.

(20) Ramon, J.; Mascaros, G. ChemElectroChem. 2015, 2, 37-50.

(21) Gong, M.; Dai, H.; Nano Research. 2015, 8, 23-39.

(22) Gong, M.; Li, Y.; Wang, H.; Liang, Y.; Wu, J. Z.; Zhou, J.; Wang, J.; Regier, T.; Wei, F.; Dai, H. J. Am. Chem. Soc. 2013, 135, 8452-8455.

(23) Hunter, B. M.; Blakemore, J. D.; Deimund, M.; Gray, H. B.; Winkler, J. R.; Müller, A. M. J. Am. Chem. Soc. 2014, 136, 13118-13121.

(24) Lu, Z.; Xu, W.; Zhu, W.; Yang, Q.; Lei, X.; Liu, J.; Li, Y.; Sun, X.; Duan, X.; Chem. Commun. 2014, 50, 6479-6482.

(25) Benito, P.; Herrero, M.; Barriga, C.; Labajos, F. M.; Rives, V. Inorg. Chem. 2008, 47, 5453

(26) Costantino, U.; Marmottini, F.; Nocchetti, M.; Vivani, R. Eur. J. Inorg. Chem. 1998, $1998,1439-1446$.

(27) Han, Y. F.; Liu, Z. H.; Yang, Z. P.; Wang, Z. L.; Tang, X. H.; Wang, T.; Fan, L. H.; Ooi, K. Chem. Mater. 2008, 20, 360.

(28) Harb, M.; Sautet, P.; Nurlaela, E.; Raybaud, P.; Cavallo, L.; Domen, K.; Basset, J-M., Takanabe, K. Phys. Chem. Chem. Phys. 2014, 16, 20548-20560.

(29) Chen, Z.; Dinh, H.N.; Miller, E. Photoelectrochemical Water Splitting Standards, Experimental Methods, and Protocols (Springer, 2013). 
(30) Abellán, G.; Coronado, E; Martí-Gastaldo, C; Pinilla-Cienfuegos, E; Ribera, A. J. Mater. Chem. 2010, 20, 7451-7455.

(31) Biesinger, M. C.; Paynec, B. P.; Grosvenor, A. P.; Lau, L. W. M.; Gerson, A. R.; Smart, R. St. C. Applied Surface Science 2011, 257, 2717-2730.

(32) Biesinger, M. C.; Paynec, B. P.; Grosvenor, A. P.; Lau, L. W. M.; Gerson, A. R.; Smart, R. St. S. Smart Surf. Interface Anal. 2009, 41, 324-332

(33) McIntyre, N. S.; Cook, M. G. Anal. Chem. 1975, 13, 2208-2213.

(34) Grosvenor, A.P.; Kobe, B.A.; Biesinger, M.C.; McIntyre, N.S. Surf. Interface Anal. 2004, $36,1564$.

(35) Luo, J.; Im, J.; Mayer, M. T.; Schreier, M.; Nazeeruddin, M. K.; Park, N.; Tilley, S. D.; Fan, H. J.; Grätzel, M. Science. 2014, 345, 1593-1596.

(36) Song, F.; Hu, Z. Nature Comm. 2014, 5, 4477.

(37) Wang, H.; Lee, H.-W.; Deng, Y.; Lu, Z.; Hsu, P.-C.; Liu, Y.; Lin, D.; Cui, Y. Nature Comm. 2015, 6, 7261.

(38) Klaus, S.; Louie, M. W.; Trotochaud, L.; Bell, A. T. J. Phys. Chem. C 2015, 119, 1830318316.

(39) Trotochaud, L.; Young, S. L.; Ranney, J. K.; Boettcher, S. W. J. Am. Chem. Soc. 2014, $136,6744-6753$. 
(40) Friebel, D.; Louie, M. W.; Bajdich, M.; Sanwald, K. E.; Cai, Y.; Wise, A. M.; Cheng, M.-J.1 Sokaras, D.; Weng, T.-C.; Alonso-Mori, R.; Davis, R. C.; Barger, J. R.; Nørskov, J. K.; Nilsson, A.; Bell, A. T. J. Am. Chem. Soc. 2015, 137, 1305-1313.

(41) Klaus, S.; Louie, M. W.; Trotochud, L.; Bell, A. T. J. Phys. Chem. C 2015, 119, 1830318316.

(42) Miles, M. H.; Kissel, G.; Lu, P. W. T.; Srinivasan, S. J. Electrochem. Soc. 1976, 123, $332-336$.

(43) Davidson, C. R.; Kissel, G.; Srinivasan, S. J. Electrochem. Soc. 1982, 132, 129-135.

(44) Hisatomi,T.; Maeda, K.; Takanabe, K.; Kubota, J.; Domen, K. J. Phys. Chem. C, 2009,113, No. 51, 21458-21466.

(45) Zhang, J. F.; Yamakata, A.; Maeda, K.; Moriya, Y.; Takata, T.; Kubota, J.; Teshima, K.; Oishi, S.; Domen. K. J. Am. Chem. Soc. 2012, 134, 8348-8351.

(46) Hisatomi,T.; Minegishi, T.; Domen, K. Bull. Chem. Soc. Jpn. 2012, 85, 647655.

(47) Hisatomi, T.; Takanabe, K.; Domen, K. Catal. Lett. 2015, 145, 95-108.

(48) Hara, M.; Hitoki, G.; Takata, T.; Kondo, J.N.; Kobayashi, H.; Domen, K. Catal. Today 2003, $78,555-560$.

(49) Nurlaela, E.; Ould-Chikh, S.; Llorens, I.; Hazemann, J.-L.; Takanabe, K. Chem. Mater. 2015, 27, 5685-5694. 
(50) van de Krol, R. Principles of photoelectrochemical cells in Photoelectrochemical Hydrogen Production, van de Krol, R.; Gratzel, M. eds., Electronic Materials: Science \& Technology 102,Springer Science, 2012.

(51) Huygens, I. M.; Strubbe, K.; Gomes, W. P. J. Electrochem. Soc. 2000, 147, 1797.

(52) Wolpert, D.; Ampadu, P. Managing Temperature Effects in Nanoscale Adaptive Systems, (Springer, 2012).

(53) Takanabe, K. Top. Curr. Chem. 2016, 371, 73-103.

(54) Le Bahers, T.; Rérat, M.; Sautet, P. J. Phys. Chem. C 2014, 118, 5997.

(55) Haynes, W. M.; Lide, D. R. Handbook of Chemistry and Physics, 92nd ed., CRC Press: Boca Raton, FL, 2011.

(56) Atkins, P.; Paula, J. D. Atkins' Physical Chemistry, 8th ed., W. H. Freeman and Company: New York, 2006.

(57) Zengm K.; Zhange, D. Prog. Energy Combs. Sci. 2010, 36, 307-326.

(58) Bard, A. J.; Faulkner, L. R. ELECTROCHEMICAL METHOD: Fundamentals and Applications. (John Wiley \& Sons, Inc., 2010).

(59) Shinagawa, T.; Takanabe, K. J. Power Sources 2015, 287, 465-471.

(60) Vázquez, G.; Alvarez, E.; Varela, R.; Cancela, A.; Navaza, J. M. J. Chem. Eng. Data $1996,41,244-248$.

(61) Mazloomi, S. K.; Sulaiman, N. Renewable Sustainable Energy Rev. 2012, 16, 4257-4263. 
(62) Hermann, C.; Dewes, I.; Schumpe, A. Chem. Eng. Sci. 50, 1995, 1673-1675.

(63) Weisenberger, S.; Schumpe, A. AIChE Journal 1996, 42, 298-300.

1

2

3

4

5

6

7

10

10

11

12

13

14

15

16

17

18

19

20

21

22

23

24

25

26

27

28

29

30

31

32

33

34

35

36

37

38

39

40

41

42

43

44

45

46

47

48

49

50

51

52

53

54

55

56

57

58

59

60 


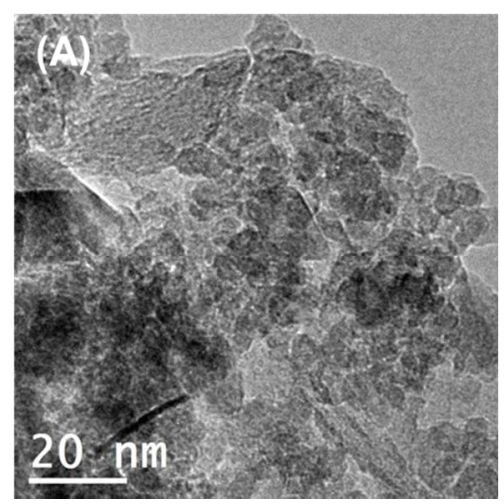

(B)

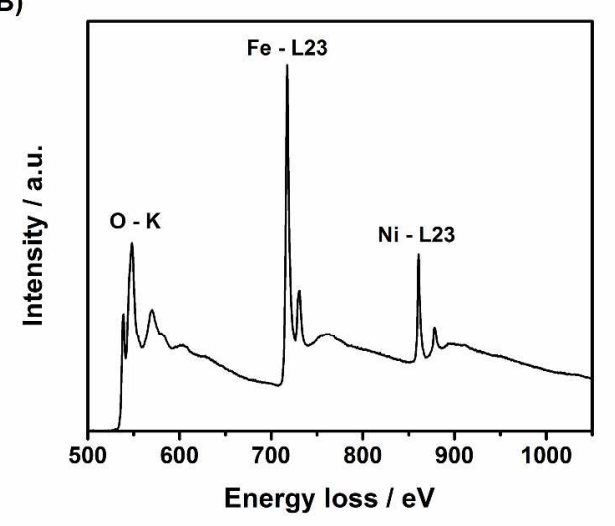

(C)

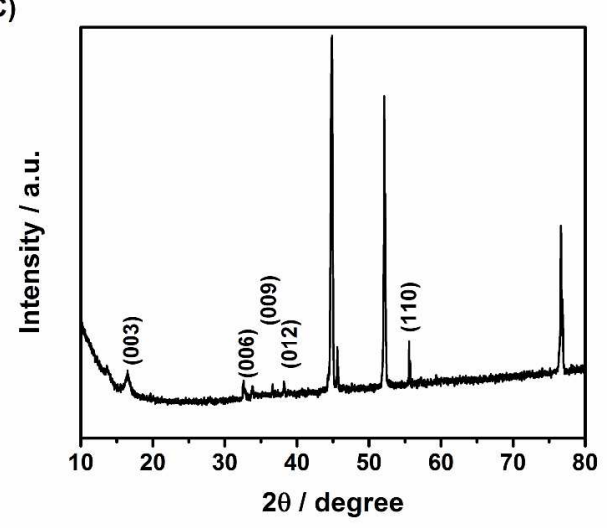

Figure 1. (A) TEM image, (B) EELS spectrum and (C) XRD pattern of $\mathrm{NiFeO}_{\mathrm{x}} / \mathrm{NF}$. 

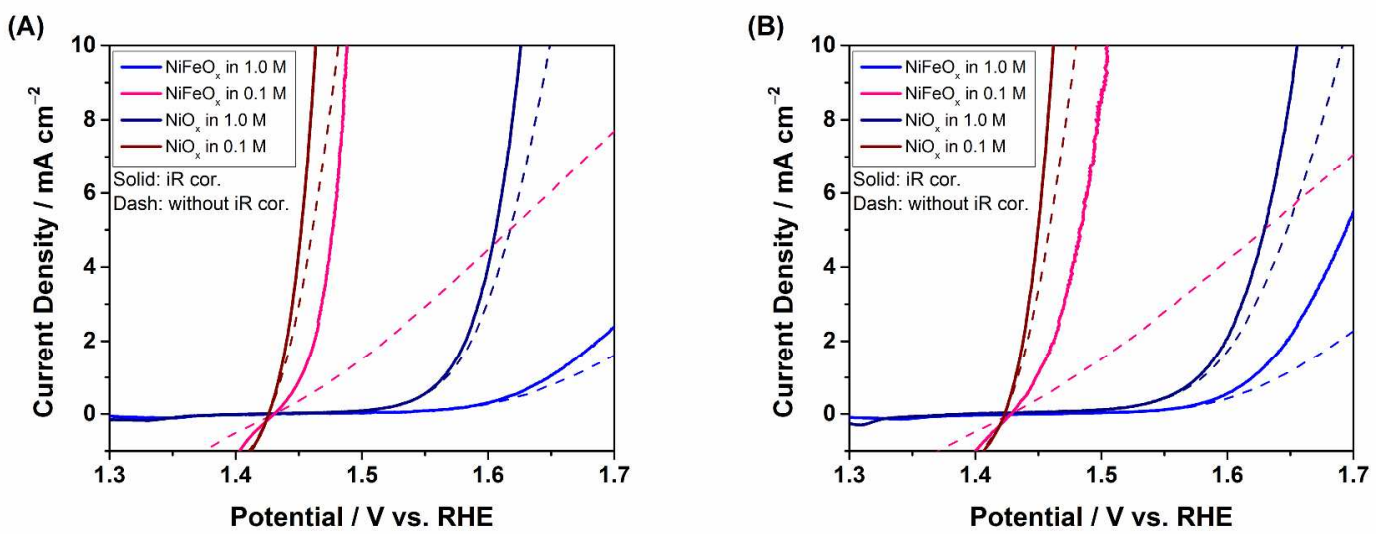

Figure 2. Linear-sweep voltammograms using a bare $\mathrm{NF}$ and $\mathrm{NiFeO}_{\mathrm{x}} / \mathrm{NF}$ catalysts in 0.1 and 1.0 $\mathrm{M}$ of (A) $\mathrm{NaOH}$ and (B) $\mathrm{KOH}$ with bubbling $\mathrm{O}_{2}$ (conditions: $1 \mathrm{mV} \mathrm{s}^{-1}, 298 \mathrm{~K}$ ). 

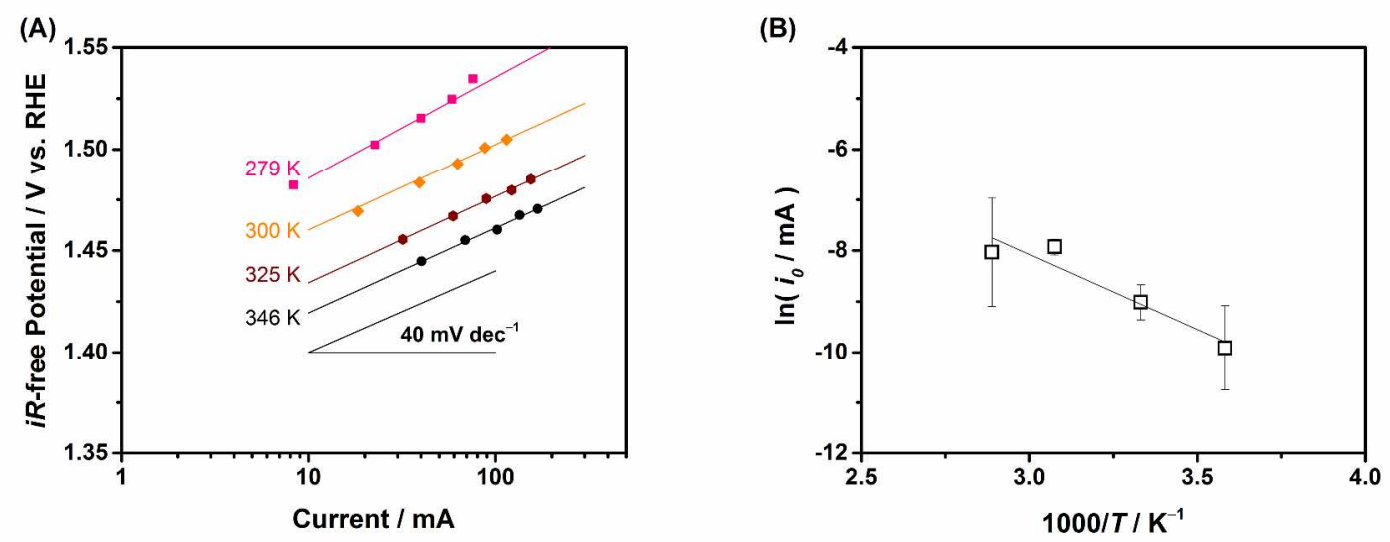

Figure 3. (A) Tafel plots for the anodic polarization over $\mathrm{NiFeO}_{\mathrm{x}} / \mathrm{NF}$ measured by chronoamperometry in $1.0 \mathrm{M} \mathrm{NaOH}$ with bubbling $\mathrm{O}_{2}$ and (B) corresponding Arrhenius plot. 
(A)

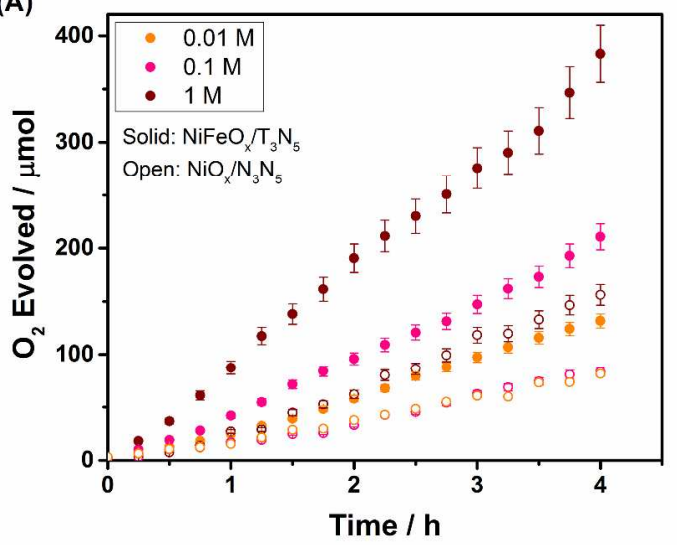

(B)

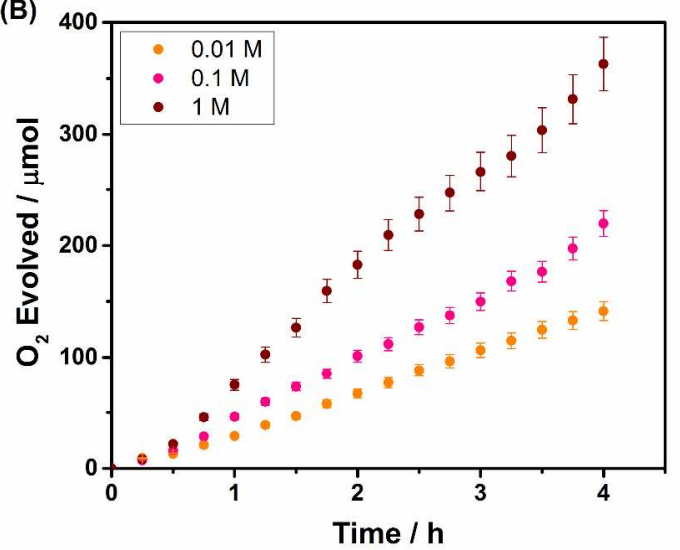

Figure 4. Photocatalytic activity time courses of $\mathrm{O}_{2}$ evolution for $2.1 \mathrm{wt} \% \mathrm{NiFeO}_{\mathrm{x}} / \mathrm{Ta}_{3} \mathrm{~N}_{5}$ in (A) $\mathrm{NaOH}$ and (B) $\mathrm{KOH}$ of various concentrations. $\left(0.1 \mathrm{M} \mathrm{Na}_{2} \mathrm{~S}_{2} \mathrm{O}_{8}, 100 \mathrm{~mL}\right.$, under visible light irradiation $(420<\lambda<800 \mathrm{~nm}))$. 


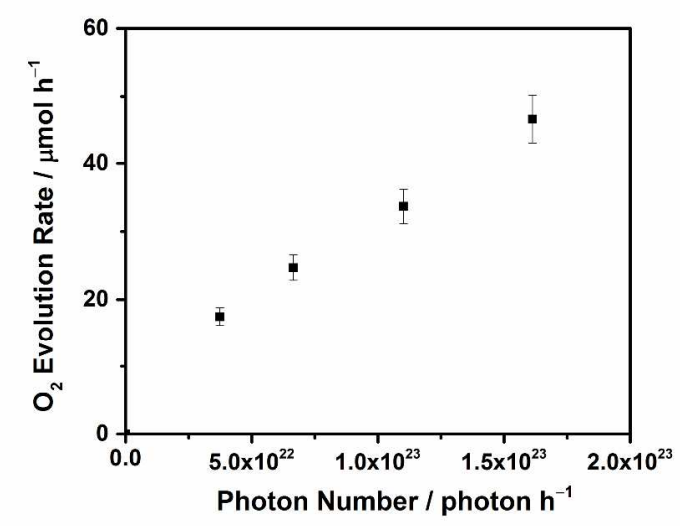

Figure 5. Photocatalytic activity time courses of $\mathrm{O}_{2}$ evolution for $2.1 \mathrm{wt} \% \mathrm{NiFeO}_{\mathrm{x}} / \mathrm{Ta}_{3} \mathrm{~N}_{5}$ with various light intensities. $\left(0.1 \mathrm{M} \mathrm{Na}_{2} \mathrm{~S}_{2} \mathrm{O}_{8}, 1.0 \mathrm{M} \mathrm{NaOH}, 100 \mathrm{~mL}\right.$, under visible light irradiation $(420<\lambda<800 \mathrm{~nm}))$. 

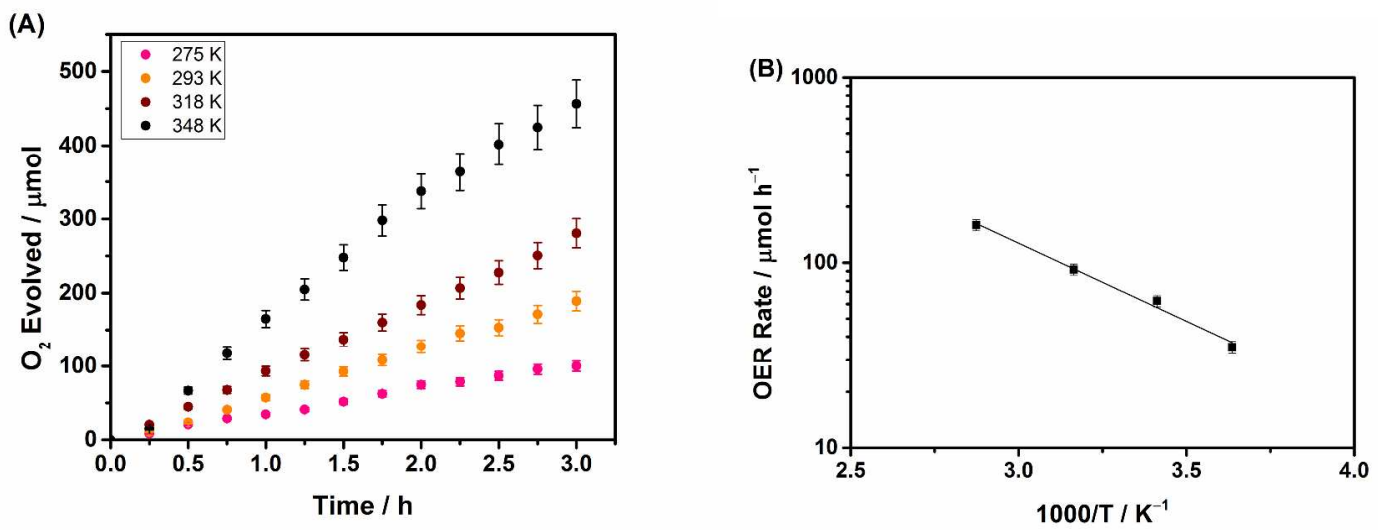

Figure 6. (A) Photocatalytic activity time courses of $\mathrm{O}_{2}$ evolution for $\mathrm{NiFeO}_{\mathrm{x}} / \mathrm{Ta}_{3} \mathrm{~N}_{5}$ at various temperatures $\left(0.1 \mathrm{M} \mathrm{Na}_{2} \mathrm{~S}_{2} \mathrm{O}_{8}, 1.0 \mathrm{M} \mathrm{NaOH}\right.$, under visible light irradiation $\left.(420<\lambda<800 \mathrm{~nm})\right)$, and (B) corresponding Arrhenius plot. 
Insert Table of Contents Graphic and Synopsis Here

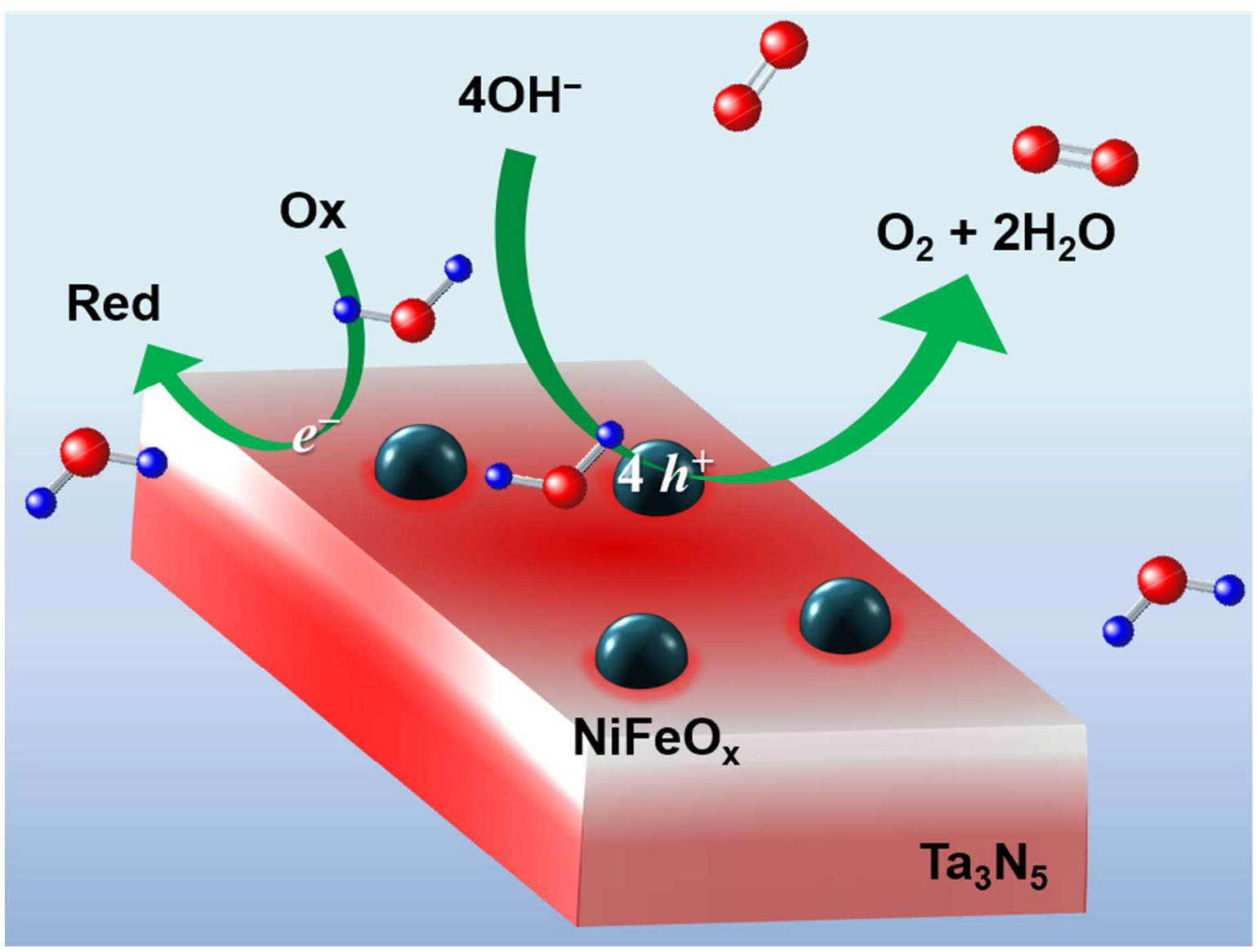

